\title{
TECHNICAL-ECONOMICAL COMPARISON BETWEEN VERTICAL LINK BEAM AND KNEE BRACE SYSTEMS IN MID-RISE STEEL BUILDINGS
}

\author{
SADEGHPOUR Mahmoud \\ Department of Civil Engineering Faculty of Shahid Bahonar, Shiraz Branch, Technical Vocational University (TVU), \\ Tehran, Iran, e-mail: dmsadegh56@gmail.com
}

Received: 06.04.2018 / Accepted: 27.07.2018 / Revised: 26.04.2019 / Available online: 31.05.2019

DOI: 10.2478/jaes-2019-0015

KEYWORDS: technical-economical, vertical, beam, steel buildings.

\begin{abstract}
:
In knee brace and shear panel systems, unlike eccentric braced frames, energy absorption is achieved through plastic deformation when sub-members yield by shear forces or bending moments caused by bracing members during severe earthquakes. Several studies have been conducted on the behavior of these two systems which resulted in design methods to obtain the best structural performance. The present study attempted to design frames using these methods, and then to compare them in terms of technical and economic factors. In this regard, to obtain a pattern of the frames behavior, a 3-span 5-storey frame was modeled for three different types of brace system (coaxial, knee and shear panel) using ANSYS software. After performing pushover nonlinear static analysis, behavior coefficients were determined and the force-lateral displacement curves of the systems were compared. In the next step, 3-span 5- 8- and 12- storey frames were analyzed and designed using ETABS software and were compared in terms of the parameters such as relative lateral displacement, normal period of system, structural weight, and shear force into foundation. The results indicate that using the above-mentioned systems, structure will exhibit more ductility which leads to reduced design base shear. The forces applied to main structural members (beams, columns, and braces) are reduced by the use of knee brace and shear panel systems. This will affect the design and sometimes increases or decreases weight of these members.
\end{abstract}

\section{INTRODUCTION}

Seeking out a suitable seismic lateral force resisting system, various systems have so far been studied or designed, among which converging braces despite very good stiffness, suffer from very poor ductility, and flexural frames despite very good ductility, have low stiffness. For this reason, Popov proposed eccentrically braced frames (EBFs) (Roeder et al., 2004) which provided both stiffness and ductility but suffered a significant disadvantage from energy depreciation in EBFs due to yielding of the main structural members. This raises problems for operation and replacement of damaged elements after an earthquake. (Aristszabalocchoa, 1990) solved this problem by proposing a knee brace system. However, this system also suffered a major defect from buckling of compression braces. Baledra introduced the knee brace frames (KBFs) which did not have the mentioned disadvantages and allows to replace damaged element after earthquake (Ming-Tuck Sam, 1995; Balendra et al., 1997 and Zahrai, 2006). Recently, shear panel system (SPS) with good stiffness and ductility has been proposed which allows to replace damaged element after earthquake (Fehling, 1992; Mofid et al., 2000). While, two of these systems proved to have good performances, they are not widely used in Iran and do not considered by engineers in the construction industry. Perhaps because they are not well known and not verified economically and technically yet. This issue is discussed in this study.

\section{RECOMMENDATIONS FOR DESIGNING KNEE MEMBER IN STEEL KBFS}

Although no codes are developed for designing knee braces, many studies have been carried out and recommendations, requirements and limitations have been made in terms of geometry and dimensions of frames. Some of these recommendations are listed below. The results of these studies are used in this paper.

Length of knee element: Yielding mode of the member under loading plays the most important role in determining length of the knee element. Behavior of the frame is different through shear and flexural yielding of the knee element. For this reason, some researchers recommend considering flexural behavior, others recommend shear behavior. Huang et al. argued that 
behavior of frame is affected by X-parameter which is defined as the ratio of vertical and horizontal lengths of the knee member to those of the frame, so that with changing X-parameter, lateral stiffness and ultimate load carrying capacity of frame is changed.

Equation 1:

$\mathrm{b} / \mathrm{B}=\mathrm{h} / \mathrm{H}=\mathrm{X}$

According to Huang et al., the optimum interval for Xparameter is $0.15<\mathrm{X}<0.5$ (Mofid and Lotfollahi, 2006) In this regard, Williams et al. stated that for flexural yielding, optimum length for knee element should be selected such that $0.15<\mathrm{X}<0.3$, and minimum length of knee member should satisfy Equation 2 (Naeim, 2001).

Equation 2:

$$
\mathrm{L}_{\mathrm{k}} \geq 4 \mathrm{M}_{\mathrm{p}} / \mathrm{V}_{\mathrm{p}}
$$

Where, MP represents plastic moment of knee element: $\mathrm{MP}_{\mathrm{P}}=\mathrm{Z} * \mathrm{FY}$

According to Baledra et al., length of knee element should be selected in a way that yielding occurs in shear mode of behavior, so Equation 3 is needed to be satisfied (Zhen, 2005).

Equation 3:

$$
V_{p}{ }^{*}=t_{w}\left(d-t_{f}\right) \sigma_{y} / 1.732 \quad, \quad M_{p}^{*}=t_{f} b\left(d-t_{f}\right) \sigma_{y} \quad \text { Where, } L_{m a x}<2 M_{p}{ }^{*} / N_{p}^{*}
$$

In the present study, length of knee element was selected to have dominating shear mode and Equation 3 was controlled for this element.

Stability of knee element: Stability of knee element should not be threatened by buckling, lateral buckling, and lateral torsional buckling. So, according to Mofid and Lotfollahi, bracing member should be connected to knee member such that minimum axial force be applied to knee member and, if possible, bracing member must be perpendicular to knee member and a joint must serve as their connection. In addition, open cross sections should not be used for knee members. Box shaped cross sections are preferred more often (Tahouni, 1996). Accordingly, in this study, box shaped cross sections were used for knee members (Farahi, 2013).

Flexural strength of knee element: Behavior of knee elements should remain within linear range during medium-sized earthquakes and lateral stiffness of structure must be preserved. Williams et al. proposed that moment of inertia equivalent to plastic modulus of knee member should be less than half the moment for column. Equation 4 shows the optimum interval for moment of inertia for yielding of knee element.

Equation 4: $0.2 \leq \mathrm{Ik} / \mathrm{Ic} \leq 0.4$
According to Huang et al., optimal mode is obtained when this ratio is equal to 0.4 (Zahrai, 2014).

Connections: Previous studies on knee brace systems indicate that it is better to use rigid connections to connect knee elements to beams and columns while using joints for other connections in steel frames with knee brace system (Zahrai, 2015).

\section{PRINCIPLES OF SHEAR PANEL DESIGN B}

There are far less studies conducted on the behavior and characteristics of shear panel systems than other brace systems. Therefore, shear panels can be designed based on the tenth code of the Iranian national building regulations for members subjected to shear. Nominal shear strength of shear panel can be calculated according to design method:

Equation 5 (if using allowable stress design):

$$
\mathrm{V}_{\mathrm{p}}=0.4 \mathrm{~F}_{\mathrm{y}} \mathrm{A}_{\mathrm{w}}
$$

Equation 6 (if using load and resistance factor design):

$$
\mathrm{V}_{\mathrm{p}}=\Phi_{\mathrm{n}} 0.6 \mathrm{~F}_{\mathrm{y}} \mathrm{A}_{\mathrm{w}}
$$

In these equations, the minimum of $\mathrm{Vp}$ mentioned above and below is used for design (Kazemzadeh Azad, 2017).

$$
\text { Equation 7: } \mathrm{M}_{\mathrm{n}}=2 \mathrm{M}_{\mathrm{p}} / \mathrm{e}
$$

Where, Aw is cross section area of web, $A w=(d-2 t f)$ tw; Fy is yield stress of steel; $\Phi$ n is strength reduction factor, $\Phi \mathrm{n}=0.9 ; \mathrm{d}$, tf, and tw are height, flange thickness and web thickness of cross section, respectively; and e is the distance between beam axis and the end of brace members. It can be seen that length of shear panel plays a significant role in structural mode of behavior so that with increasing it, yielding mode of shear panel turns from shear into flexure. This length is calculated by Equation 8 and must lead to shear mode of behavior so that $\mathrm{Mn}>\mathrm{Vp}$.

Equation 8:

$\mathrm{Lsp}=\mathrm{e}-0.5 \mathrm{hb}$

Meanwhile, due to similar behavior of knee element and vertical link beam to the behavior of link beam in EBF system, regulations of EBF system design are also used in design of new systems.

\section{MODELS AND LOADINGS}

Before modeling, geometry of models and loading must be described. For example, (Figure 1) illustrates the general form of 5-storey models considering the proposed systems as lateral load resisting system. 


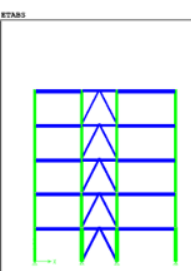

(a)

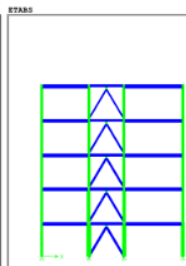

(b)

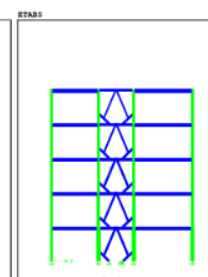

(c)
Figure 1. General form of the examined models for a 5storey frame; (a) coaxial bracing; (b) shear panel bracing; (c) knee bracing

For analysis and design of these frames, it is assumed that ceiling and walls exert a uniform distributed load of $4 \mathrm{t} / \mathrm{m}$ on columns. In order to consider the effect of loads exerted on columns in different directions, a point load of 10 tons is applied to columns at each floor level as shown in Figure 2.

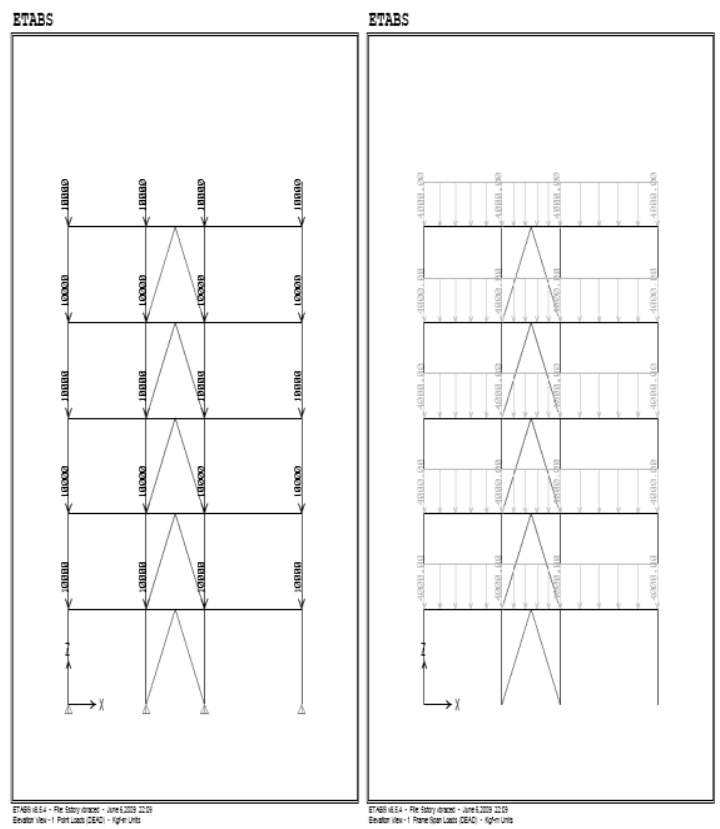

Figure 2. Gravity loads applied acting on structure; Poin load of 10 tons acting on columns at each floor level

Seismic coefficients for these frames are calculated based on 2800 Iranian Code of Practice for Seismic Resistant Design of Buildings. Table 1 gives the parameters determining seismic coefficient for each model.

Table 1. Seismic coefficients for the examined models

\begin{tabular}{|c|c|c|c|c|c|c|c|c|c|c|}
\hline Type & $\begin{array}{c}\text { Number of } \\
\text { story }\end{array}$ & $\begin{array}{c}\text { mode } \\
\text { l no. }\end{array}$ & $\mathrm{A}$ & $\mathrm{I}$ & $\mathrm{T}_{0}$ & $\mathrm{~T}_{\mathrm{s}}$ & $\mathrm{S}$ & $\mathrm{B}$ & $\mathrm{R}$ & $\mathrm{C}$ \\
\hline CBF & 5 & 1 & 0.3 & 1 & 0.15 & 0.7 & 1.75 & 2.75 & 6 & 0.1375 \\
\cline { 2 - 12 } & 8 & 2 & 0.3 & 1 & 0.15 & 0.7 & 1.75 & 2.75 & 6 & 0.1375 \\
\cline { 2 - 11 } & 12 & 3 & 0.3 & 1 & 0.15 & 0.7 & 1.75 & 2.66 & 6 & 0.1330 \\
\hline \multirow{3}{*}{ SPS } & 5 & 4 & 0.3 & 1 & 0.15 & 0.7 & 1.75 & 2.75 & 7 & 0.1187 \\
\cline { 2 - 11 } & 8 & 5 & 0.3 & 1 & 0.15 & 0.7 & 1.75 & 2.75 & 7 & 0.1187 \\
\cline { 2 - 11 } & 12 & 6 & 0.3 & 1 & 0.15 & 0.7 & 1.75 & 2.66 & 7 & 0.114 \\
\hline KBF & 5 & 7 & 0.3 & 1 & 0.15 & 0.7 & 1.75 & 2.75 & 7 & 0.1187 \\
\cline { 2 - 11 } & 8 & 8 & 0.3 & 1 & 0.15 & 0.7 & 1.75 & 2.75 & 7 & 0.1187 \\
\cline { 2 - 10 } & 12 & 9 & 0.3 & 1 & 0.15 & 0.7 & 1.75 & 2.66 & 7 & 0.114 \\
\hline
\end{tabular}

Table 1 shows that seismic coefficient for each of the considered structural systems can be determined according to the type of system and height of the frame.
Pushover nonlinear static analysis was performed on these models. In this method, lateral loads at floor levels are introduced into the model considering uniform and triangular patterns. At each loading step, displacements and other available outputs are extracted from the models. Gravity load is also entered into the system in a linear analysis before performing the nonlinear analysis. The nonlinear analysis under lateral loading is started when the linear analysis under gravity loading is completed. Figure 3 shows the two load distribution patterns examined in this study (Miri et al., 2009).

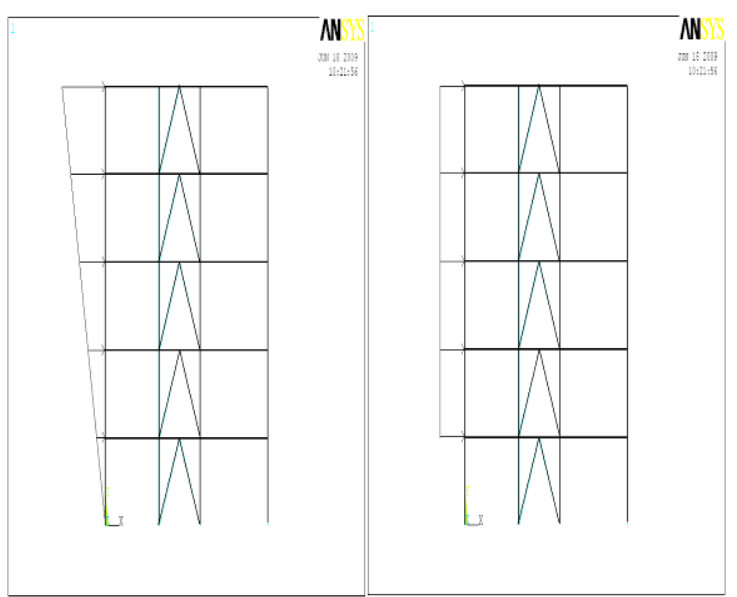

Figure 3. Uniform and triangular load distribution patterns

By performing linear analysis under gravity loads, we can see deformations of the studied frames as shown in Figure 4.

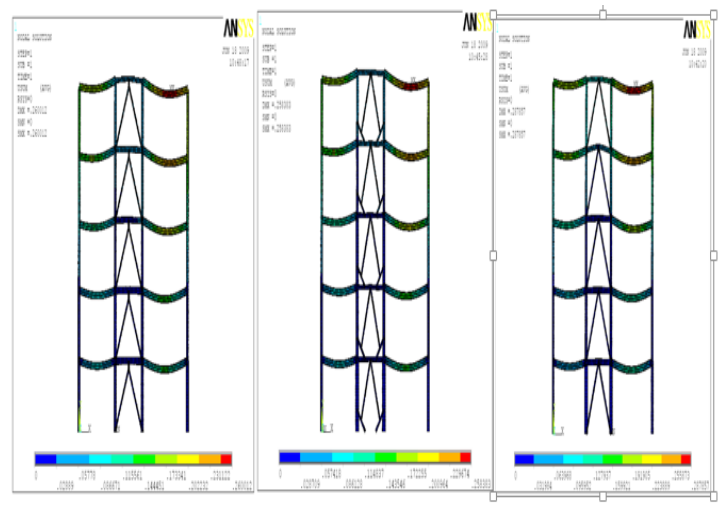

Figure 4. Deformations of the studied frames

According to Figure 4, it can be seen that behavior of the frames when subjected to gravity loads was in accordance with the behavior expected from simple braced steel frames.

\section{NONLINEAR ANALYSIS UNDER LATERAL LOADS}

After linear analysis under gravity loads, a nonlinear analysis was performed considering lateral loads according to the lateral load patterns introduced above. In this section, the frames with coaxial, knee, and shear panel brace systems were analyzed and the results compared to each other. Figure 5 illustrates deformation 
of the coaxial braced frame within linear range of behavior (at the beginning of loading), and nonlinear range of behavior (at the end of loading). The analysis is stopped when the von Mises stress exceeds the ultimate value defined for the material.

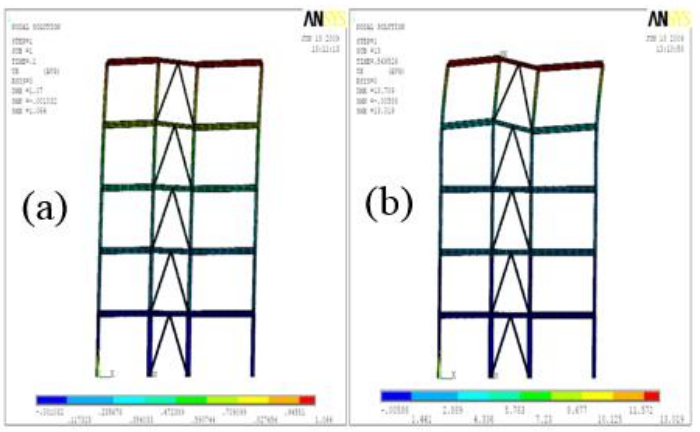

Figure 5. Deformation of the coaxial braced frame under lateral loading; (a) By applying 10\% of lateral forces; (b) by applying $55 \%$ of lateral forces

Figures 6 and 7 illustrate force-lateral displacement curves under triangular and uniform load patterns, respectively. Using these curves, the parameters associated to nonlinear behavior of these systems were obtained and compared to each other.

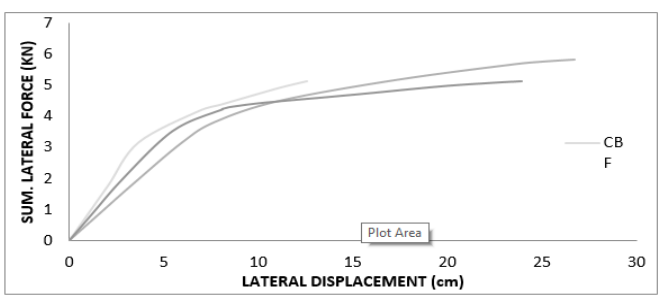

Figure 6. Force-lateral displacement curves for the studied frames under triangular load pattern

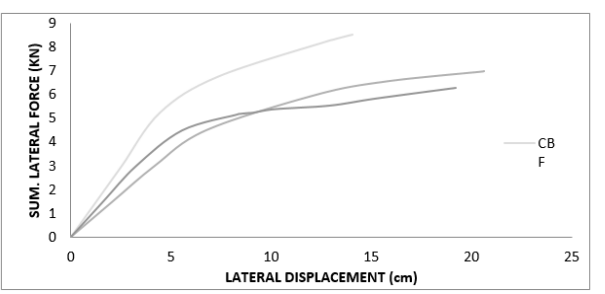

Figure 7. Force-lateral displacement curves for the studied frames under uniform load pattern

From Figures 5 and 6, it can be seen that in triangular load pattern, load carrying capacity of structure is significantly less than uniform pattern. This is due to the difference in load distribution between different members and elements. By comparing the above curves, we can see that with the use of knee brace instead of CBF, load carrying capacity of structure is significantly increased and the maximum deformation of structure is approximately doubled. This indicates the extraordinary energy absorption capacity of this system compared with coaxial brace system. Moreover, behavior coefficients of $\mathrm{CBF}, \mathrm{KBF}$, and SPS systems were 44.5, 9.5, and 10.08, respectively, according to force-lateral displacement curves (Figures 5 and 6).

\section{TECHNICAL COMPARISON}

The analysis results are summarized in Table 2 , according to the models obtained for different brace systems based on the number of floors and type of bracing.

Table 2. The results obtained from analysis of the models

\begin{tabular}{|c|c|c|c|c|c|}
\hline $\begin{array}{c}\text { Model } \\
\text { no. }\end{array}$ & $\begin{array}{c}\text { Model } \\
\text { description }\end{array}$ & $\begin{array}{l}\max \\
\text { disp. } \\
\text { (cm) }\end{array}$ & $\begin{array}{l}\text { Base } \\
\text { shear } \\
\text { (ton) }\end{array}$ & $\begin{array}{c}\text { Period } \\
(\mathrm{sec})\end{array}$ & $\begin{array}{l}\text { Lateral } \\
\text { stiffness } \\
\text { (ton } / \mathrm{cm})\end{array}$ \\
\hline 1 & 5story-cbf & 5.619 & 61.404 & 0.964 & 10.9 \\
\hline 2 & 5story-SPS & 6.061 & 53.043 & 1.087 & 8.8 \\
\hline 3 & 5story-KBF & 5.718 & 53.021 & 1.054 & 9.3 \\
\hline 4 & 8 story-cbf & 16.086 & 98.72 & 1.5466 & 6.1 \\
\hline 5 & 8story-SPS & 19.08 & 85.27 & 1.8494 & 4.5 \\
\hline 6 & 8story-KBF & 16.41 & 85.26 & 1.7012 & 5.2 \\
\hline 7 & 12story-cbf & 37.51 & 144.47 & 2.318 & 3.9 \\
\hline 8 & $\begin{array}{l}\text { 12story- } \\
\text { SPS }\end{array}$ & 41.09 & 123.77 & 2.6521 & 3.0 \\
\hline 9 & $\begin{array}{l}\text { 12story- } \\
\text { KBF }\end{array}$ & 34.3 & 123.87 & 2.4019 & 3.6 \\
\hline
\end{tabular}

According to the above table, the examined parameters include maximum displacement (max disp), static base shear, period and lateral stiffness.

Table 2 indicates that:

1- In all these three systems, with increasing number of floors, lateral displacement is increased, but this increasing trend is slower in knee brace system than the other two systems.

2- In 5-storey frames, there is no significant difference between ultimate displacements, but the difference becomes greater with increasing height so that in 12storey frames the difference is clearly evident between these three brace systems.

3- With increasing height, the ultimate displacement of knee brace system becomes less than shear panel which is a good advantage for this system during earthquake.

4- The static base shear for both knee brace and shear panel systems is about $13.8 \%$ less than coaxial braced frame which is a good advantage for these systems.

5- Comparison of normal period of structure in the first mode of vibration showed that in frames with different height, the maximum period was related to shear panel, knee, and coaxial brace systems, respectively.

6- With increasing height, lateral stiffness of knee bracing was less decreased than the two other systems. This advantage can be seen in Figure 8. 


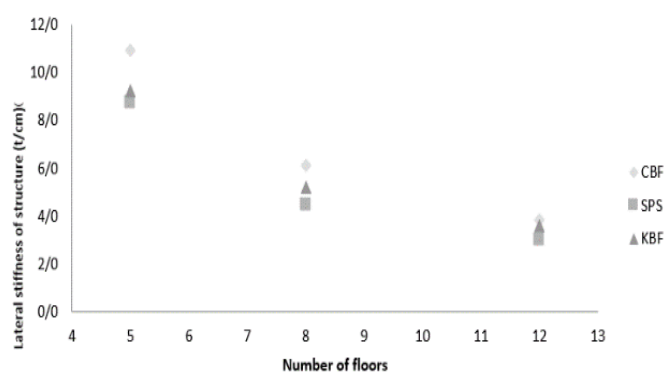

Figure 8. Lateral stiffness of structure based on structural system and number of floors

\section{ECONOMICAL COMPARISON}

Economic justification is of the most important analyses in any structural system because a system might not be economically justified, despite being technically appropriate. Therefore, in this study, the brace systems were designed based on the tenth code of the Iranian national building regulations, and then analyzed economically according to weight parameter. The following results are obtained according to Table 3 .

\begin{tabular}{|c|c|c|c|c|c|c|c|}
\hline \multirow{2}{*}{$\begin{array}{c}\text { Model } \\
\text { no. }\end{array}$} & $\begin{array}{c}\text { Model } \\
\text { description }\end{array}$ & $\begin{array}{c}\text { max } \\
\text { Uplift } \\
\text { (ton) }\end{array}$ & & \multicolumn{5}{|c|}{ Weight (Kg) } \\
\cline { 4 - 8 } & & & Column & Beam & Brace & $\begin{array}{c}\text { Knee/ } \\
\text { SP }\end{array}$ & $\begin{array}{c}\text { total } \\
\text { (Kg) }\end{array}$ \\
\hline 1 & 5 story-CBF & 225.0 & 3432 & 2893 & 865 & N/A & 7190 \\
\hline 2 & 5 story-SPS & 194.2 & 3397 & 3298 & 604 & 136 & 7435 \\
\hline 3 & 5 story-KBF & 188.9 & 3499 & 2846 & 698 & 242 & 7285 \\
\hline 4 & 8 story-CBF & 558.4 & 8701 & 4660 & 1781 & N/A & 15142 \\
\hline 5 & 8 story-SPS & 482.3 & 8457 & 5362 & 1040 & 567 & 15426 \\
\hline 6 & 8 story-KBF & 485.0 & 9043 & 4662 & 1102 & 628 & 15435 \\
\hline 7 & 12 story-CBF & 1199.0 & 21591 & 7045 & 3643 & N/A & 32279 \\
\hline 8 & 12 story-SPS & 1028.0 & 20624 & 7995 & 1991 & 913 & 31523 \\
\hline 9 & 12 story-KBF & 1040.6 & 21710 & 7124 & 3209 & 492 & 32535 \\
\hline
\end{tabular}

Table 3. The results obtained from design of the models

Weight of the columns is one of the most important parameters for comparison. In this study, weight of columns in knee system was $2 \%$ higher than its equivalent coaxial system. Also, weight of columns in shear panel system was $3 \%$ lower than the equivalent coaxial system.

Due to the fact that joints were selected as beam to column connections in these models and simple frames were considered, beams do not play a significant role in bearing seismic forces. However, in SPS system, weight of beams was greater than the other two systems due to the shear force transmitted from the brace system to the beam. Weight of beams in SPS system was $14 \%$ greater than the two other systems, which is a disadvantage of this system compared with the two other systems.

As you can be seen, bracing members in CBF system have the maximum weight among the three systems. According to this table, weight of bracing members in
SPS and KBF systems was reduced by $39 \%$ and $23 \%$, respectively, compared with CBF system. However, SPS and KBF systems use sub-members and weight of these sub-members should be considered in analyses. For example, SPS system reduces weight of bracing members and columns, but increases weight of beams. In addition, an overweight is imposed on the system due to shear panel members. This can be considered as a disadvantage of this system. Figure 9 shows the total weight of structure for these three systems.

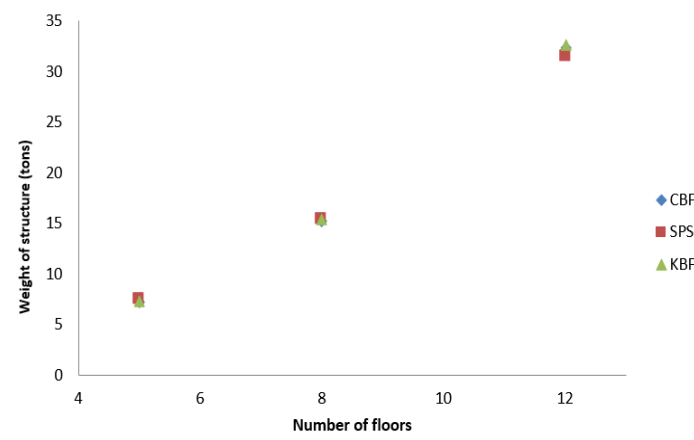

Figure 9. Weight of structural members based on structural system and number of floors

From Figure 9, it can be seen that if all members are taken into account, weight of structure is approximately identical in all these three systems. So, by replacing CBF system with novel KBF and SPS systems, the total weight of system cannot be significantly reduced. This issue can be discussed further. The use of KBF and SPS systems will change behavior coefficient of structure. Based on the calculations in section 5, behavior coefficient of these two systems is more than the value considered in these experiments cautiously. In the next section, the effect of brace system type on foundation is discussed. Seismic codes consider the force generated in the columns adjacent to bracing members as an effective factor in designing foundation. CBF generates very large force at the bottom of the adjacent columns which highly affects the design. This force is the uplift force in Table 3 . It can be seen that with the use of SPS and KBF systems, on average, uplift force can be reduced by $14 \%$, which has a very positive effect on the design of foundation.

\section{CONCLUSION}

The elastic lateral stiffness of knee brace system is higher than shear panel system which results in less lateral displacement under the same conditions. With increasing height, reduction of lateral stiffness in knee brace system is less than shear panel system. By comparing weight of the same frames with different brace systems, it can be seen that on average, weight of columns in knee braced frames was $2 \%$ higher than coaxial braces. However, weight of columns in shear panel system was 3\% lower than coaxial system. In the models studied here, weight of beams in shear panel system was higher than the two other systems. For the same frame, weight of beams in shear panel system was $14 \%$ greater than coaxial system. In addition, weight of braces in knee brace and shear 
panel systems was reduced by $23 \%$ and $39 \%$, respectively, compared with coaxial system. However, the total weight of members in the same frame, taking into account knee and shear sub-members, was almost identical in all three systems. With the use of knee brace and shear panel systems, the uplift force at the bottom of the columns adjacent to bracing members was reduced by $14 \%$.

Although, the behavior coefficients considered in the design of the studied frames did not reduce weight of the structures with knee brace and vertical shear panel systems compared with coaxial brace system, but as shown in this paper, behavior coefficients of knee brace and vertical shear panel systems are much higher than coaxial brace system. With the use of these coefficients in the design of frames, total weight of structure will be certainly reduced significantly

\section{References:}

Roeder, C.W, Lehman, D.E, Yoo J. H, "PerformanceBased Seismic Design of Braced-Frame Gusset Plate Connections", Connections in Steel Structures VAmsterdam - June 3-4, 2004.

Aristszabal-occhoa JD. "Disposable Knee Bracing: improvement in seismic design of steel frames" journal of structural engineering, ASCE 1986; 112(7): 1544-52 Balendra T., "Diagonal Brace with Ductile Knee Anchor for and Seismic Steel Frames", Journal of Earthquake Engineering Structural Dynamics, Nol.19, 1990, pp. 847858

Ming-Tuck Sam Thambirajah Balendra and Chih-Young Liaw, "Earthquake-resistant steel frames with energy dissipating knee elements", Engineering Structures Volume 17, Issue 5, June 1995, Pages 334-343.

Balendra, T, E L Lim and C Y Liaw, "Large scale seismic testing of knee-brace-frame.", Journal of Structural Engineering, ASCE, 123, 1 (1997): 11-19.

Zahrai S.M, Moslehi Tabar.A, "Cyclic behavior of steel braced frames having Shear Panel systems", Asian Journal of civil engineering (Building and housing) VOL. 7, NO.1 (2006), 13-26.

Fehling E., Pauli W. Bauwkamp j.g. (1992) "Use of vertical shear link in Eccentrically Braced frames", Earthquake Engineeng, tenth Wird conference 1992.

Mofid M., Khosravi, P., "Nonlinear analysis of Disposable Knee Bracing", Computers and Structures, Vol. 75, 65-72, 2000.

Massood Mofid, Mehrdad Lotfollahi, "On the characteristics of new ductile knee bracing systems", Journal of Constructional Steel Research 62 (2006) 271281.

Massood Mofid, Mehrdad Lotfollahi, "On the design of new ductile knee bracing systems", Journal of Constructional Steel Research 62 (2006) 282-294.
Naeim, F., "The seismic design handbook", 2nd edition, 2001, VNR, New York

Federal Emergency Management Agency (FEMA), "Prestandard and Commentary for the Seismic Rehabilitation of Buildings", FEMA 356 / November 2000 .

HUANG Zhen, LI Qing-song, CHEN Long-zhu, "Elastoplastic analysis of knee bracing frame", Journal of Zhejiang University SCIENCE, ISSN 1009-3095, 2005 6A(8):784-789.

Tahouni, Sh. (1998). Design of steel structures based on the Iranian steel design code, 2nd edition.

Building and housing research center, 2800 Iranian Code of Practice for Seismic Resistant Design of Buildings, 1999.

Farahi, M., Mofid, M. (2013). "On the quantification of seismic performance factors of Chevron Knee Bracing, in steel structures", Engineering Structures, Vol. 46, pp. 155-164.

Zahrai, S.M., Jalali, M. (2014). "Experimental and analytical investigation on seismic behavior of ductile steel knee braced frames", Steel and Composite Structures, an Intl. Journal, Vol. 16, No. 1, pp. 1-21.

Zahrai, S.M. (2015). "Cyclic Testing of Chevron Braced Steel Frames with IPE shear panels", Steel and Composite Structures, an Intl. Journal, Vol. 19, No. 5, pp. 1167-1184.

Kazemzadeh Azad, S., Topkaya, C. (2017). "A review of research on steel eccentrically braced frames", Journal of Constructional Steel Research, Vol. 128, pp. 53-73.

Miri, M., Zare, A., Abbaszadeh, H. (2009). "Seismic behavior of steel frames investigation with knee brace based on pushover analysis", International Journal of Civil, Environmental, Structural, Construction and Architectural Engineering Vol: 3, No: 2, pp. 122-128. 